\title{
Pathways and patterns of cell loss in verified Alzheimer's disease: a factor and cluster analysis of clinico-pathological subgroups
}

\author{
H. Förstl ${ }^{1}$, R. Levy ${ }^{1}$, A. Burns ${ }^{1}$, P. Luthert ${ }^{2}$ and N. Cairns ${ }^{3}$ \\ ${ }^{1}$ Section of Old Age Psychiatry, ${ }^{2}$ Department of Neuropathology and ${ }^{3} \mathrm{MRC}$ Alzheimer's Disease \\ Brain Bank, Institute of Psychiatry, London, UK \\ Correspondence to: H. Förstl, Central Institute of Mental Health, PO Box 122 120, J5, 68159 \\ Mannheim, Germany
}

\begin{abstract}
Thirty-seven patients with neuropathologically verified Alzheimer's disease (AD) have been studied prospectively. A principal components analysis of neuron numbers in cortical and subcortical areas revealed two variables: Variable I with high loadings for the hippocampo-parahippocampo-parietal neuron counts and Variable II with high loadings for coeruleo-frontal cell numbers. Both may reflect functional neuroanatomical connections which may act as pathways of neurodegeneration in AD. A cluster analysis based on these neuron numbers yielded three groups of patients: Cluster A with low hippocampoparahippocampo-parietal cell counts, Cluster B with well-preserved neuron numbers, and Cluster $C$ with low coeruleo-frontal neuron numbers. Differences in clinical features between these patient groups indicated the potential clinical relevance of these clusters.
\end{abstract}

Keywords: Alzheimer's disease, neurodegeneration, sub-groups, neuropathology

\section{INTRODUCTION}

Alzheimer's disease (AD) manifests a large variety of clinical symptoms and signs, course characteristics and neuroradiological or neuropathological changes (Burns et al., 1990a). Several attempts have been made to characterize clinical "subtypes" of $\mathrm{AD}$ and to corroborate these distinctions by post-mortem evidence of different types of underlying pathology (Berrios, 1985; Jorm, 1985; Bondareff et al., 1987). Because of the paucity of clinico-pathological studies, it is still unclear whether the clinical heterogeneity of $\mathrm{AD}$ is related to different patterns of neurodegeneration which may develop along different functional pathways (Pearson et al., 1985; Hertz, 1989).

Clinical or neuropathological evidence for different subtypes of $\mathrm{AD}$ should be validated by external criteria (Jorm, 1985; Mohr et al., 1990). We have therefore examined both neuropathological and clinical variables in patients with verified $\mathrm{AD}$. The following questions were addressed using principal components and cluster analysis:

(1) Can the variation of neuron counts in different brain areas be explained by principal components related to functional neuroanatomical pathways?

(2) Can different patterns of neuronal loss be de-

(C) 1994 Rapid Communications of Oxford Ltd tected which distinguish different clusters of patients?

(3) Are these potential subtypes of $\mathrm{AD}$ associated with other characteristic clinical features?

\section{METHODS}

Demographic characteristics of the patient sample, details about the prospective clinical examination and the neuropathological work-up have been published in previous papers (Burns et al., 1990a; Förstl et al., 1992a). The clinical diagnosis of $\mathrm{AD}$ according to NINCDS-ADRDA criteria (McKhan 1984 etal) was verified neuropathologically in 56 of the first 65 patients from a prospective longitudinal study who came to post-mortem examination (Förstl et al., 1992a). The clinical examination was last administered within 12 months before death. It included the Clinical Dementia Rating (CDR; Berg, 1984), the Cambridge Cognitive Examination (CAMCOG; Roth et al., 1986), the Geriatric Mental State Schedule (GMSS; Copeland et al., 1976; Gurland et al., 1976) and a standardized neurological examination (Burns et al., 1990b).

Behavioural Neurology . Vol 7 . 1994 175 
TABLE I. Principal components analysis of neuron counts in different brain areas of 37 patients with verified Alzheimer's disease. The Eigenvalues refer to the variances of the unrotated principal components, whereas the loadings refer to the rotated variables

\begin{tabular}{lrr}
\hline & \multicolumn{2}{c}{ Factor } \\
\cline { 2 - 3 } & \multicolumn{1}{c}{ I } & \multicolumn{1}{c}{ II } \\
\hline Eigenvalue & 2.03 & 1.58 \\
Percentage of variance & & \\
$\quad$ explained & $29 \%$ & $23 \%$ \\
Parietal lobe (Area 7) & 0.81 & -0.06 \\
Parahippocampal gyrus & 0.80 & 0.17 \\
Hippocampus (CA1) & 0.73 & -0.01 \\
Frontal lobe (Area 32) & 0.14 & 0.72 \\
Locus coeruleus & -0.10 & 0.85 \\
Dorsal raphe nucleus & 0.16 & -0.22 \\
Substantia nigra & 0.16 & 0.44 \\
\hline
\end{tabular}

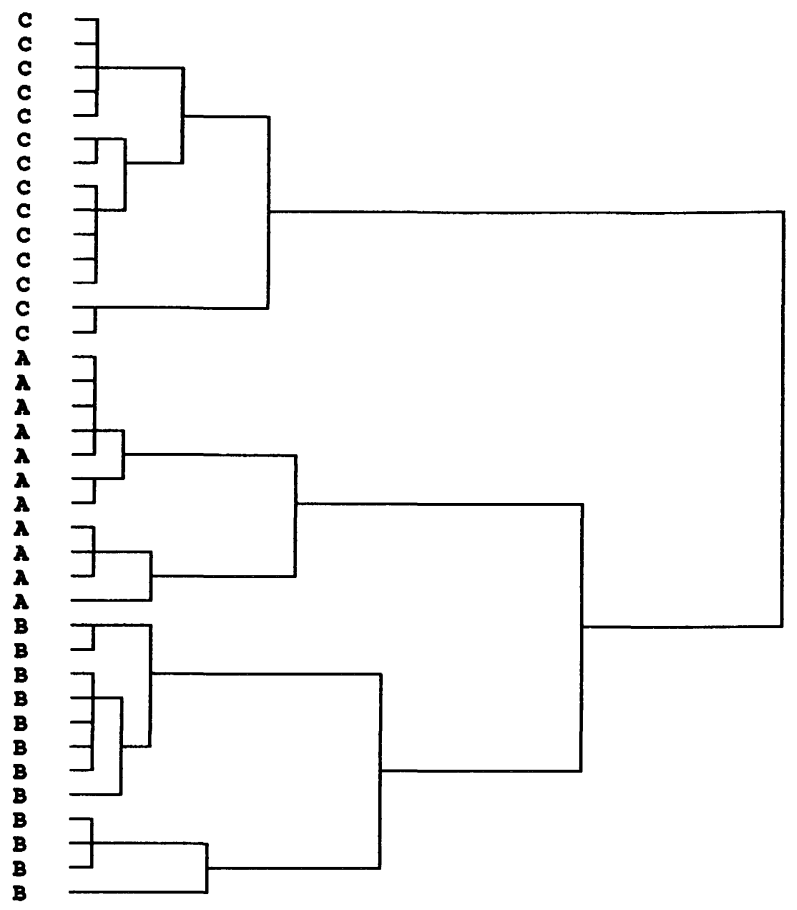

FIG. 1. Dendrogram demonstrating the hierarchical cluster structure based on cortical and subcortical neuron counts (A, B and C indicate cluster membership referring to Table II).

The following tissue blocks were taken from the brains, fixed in $10 \%$ formol saline and embedded in paraffin wax: frontal lobe (including Area 32), parietal lobe (Area 7), mediotemporal lobe (parahippocampal gyrus, hippocampus), mesencephalon (substantia nigra) and pons (including the largest diameter of the locus coeruleus and the dorsal raphe nucleus; Förstl et al., 1992a). Fourteen $\mu \mathrm{m}$ sections were stained according to Klüver Barrera and impregnated with silver according to Glees and Marsland. Our earlier analyses had shown significant associations between the clinical features and neuronal change, therefore we decided to study neurons, and not plaques and tangles. Large neurons were defined as Nissl-positive, nucleolated cells with a maximum diameter of more than $20 \mu \mathrm{m}$ in cortex (layer III), hippocampus (pyramidal cell layer of the CA1 field), substantia nigra and locus coeruleus, and of more than $25 \mu \mathrm{m}$ in the dorsal raphe nucleus. All counts reported in this paper were carried out visually with an ocular grid at $\times 400$ magnification. Numbers are given as counts per $\mathrm{mm}^{2}$ for the cortical and hippocampal areas and as counts per nucleus per horizontal section for the brainstem nuclei. The examiner was blind to the clinical findings. A complete set of artefactfree slides and stains was available from 37 cases.

Variables accounting for the variance of cell numbers in different brain areas of the patients with verified $\mathrm{AD}$ were extracted with principal components analysis (Everitt and Dunn, 1983). The neuron counts were standardized using a z-transformation and the components were transformed orthogonally (Varimax rotation). Ward's method of cluster analysis was employed to differentiate the patterns of cell loss in the patient sample (Ward, 1963; Everitt, 1989). The differences of neuron numbers between the clusters were examined with a one-way analysis of variance and Scheffe's test for multiple comparisons (Maxwell and Delaney, 1990). The data analysis was carried out with SPSS /PC + (Norusis, 1988).

\section{RESULTS}

A complete set of clinical and neuropathological data was available from 37 of 56 patients with neuropathologically verified AD. Principal components analysis based on the neuron counts in the frontal lobe (Area 32), parietal lobe (Area 7), the parahippocampal gyrus, the hippocampal CA1 field, the substantia nigra, locus coeruleus and dorsal raphe nucleus yielded two variables with Eigenvalues higher than 1 which accounted for $52 \%$ of the observed variance (Table I). Variable I accounted for $29 \%$ of the observed variance and showed high loadings for the cell counts in the hippocampus, parahippocampal gyrus and parietal lobe, indicating that the neuron numbers in these areas tended to vary together. Variable II had high loadings for the neuron numbers in the locus coeruleus and frontal lobe (Area 32).

The dendrogram of a cluster analysis based on these two variables is shown in Fig. 1. In a three cluster solution, 11 patients formed Group A 


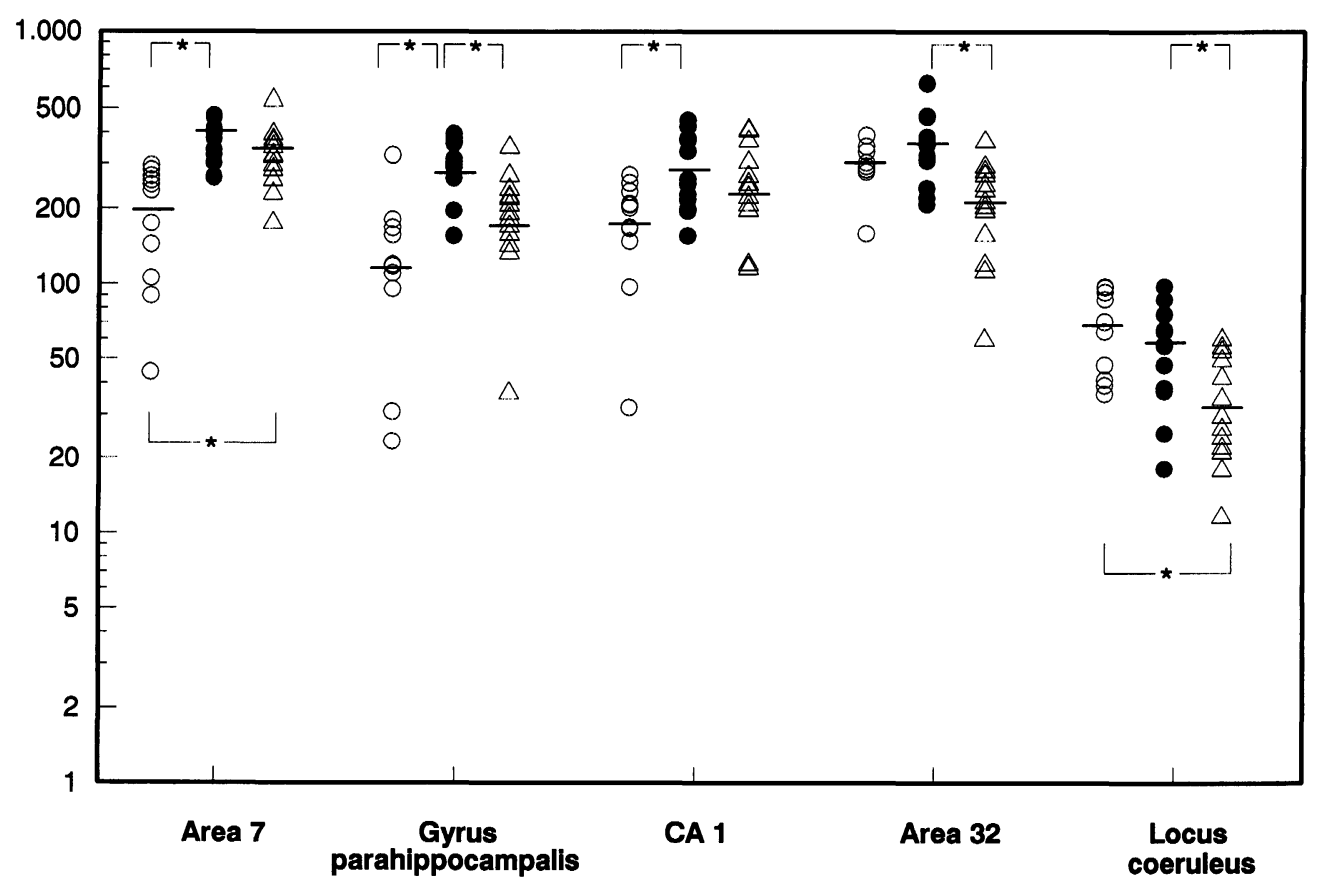

FIG. 2. Differences of neuron counts in the parietal lobe $(F=9.0, p<0.001)$, parahippocampal gyrus $(F=17.0, p<0.001)$, area $C A 1$ of the hippocampus ( $F=3.8, p<0.05)$, frontal lobe $(F=8.3, p<0.01)$ and locus coeruleus $(F=9.3, p<0.001$ ) between the patients in Cluster $A(O)$, Cluster $B(0)$ and Cluster $C(\Delta)$. *Significant between-cluster differences $(p<0.05)$ after application of Scheffe's test for multiple comparisons.

which was characterized by low hippocampoparahippocampo-parietal neuron numbers (Fig. 2). Twelve patients formed Group B with well-preserved cortical and subcortical neuron numbers, but mildly decreased counts in the dorsal raphe nucleus. Group C consisted of 14 patients with predominant coeruleofrontal cell loss. Solutions with larger cluster numbers will not be presented because of the small sample sizes.

The patients belonging to Cluster $\mathrm{C}$ had the earliest onset, the longest duration of illness, the highest rate of "frontal" release signs and the greatest density of intraneuronal neurofibrillary tangles (Table II). Depressive disturbances were least frequent in the group with the highest neuron counts in the locus coeruleus (Cluster A). Most delusions and hallucinations were observed in Cluster B. There were no significant differences between the groups regarding the clinical stage of dementia during the last year of life or performance on the last cognitive test administered.

\section{DISCUSSION}

The results can be summarized as follows:

(1) Principal components analysis revealed two variables underlying more than $50 \%$ of the observed variance of neuron numbers: a "hippocampo-
TABLE II. Demographic and clinical features in three clusters of patients with verified Alzheimer's disease. None of the observed differences was statistically significant $(p>0.05)$

\begin{tabular}{llll}
\hline & \multicolumn{3}{c}{ Cluster } \\
\cline { 2 - 4 } & $\mathrm{A}$ & $\mathrm{B}$ & $\mathrm{C}$ \\
\hline$n$ (ठ $^{*} /$ o) & $11(3 / 8)$ & $12(5 / 7)$ & $14(2 / 12)$ \\
Age of onset (years) $^{1}$ & $80(64-88)$ & $77(60-87)$ & $72(58-90)$ \\
Duration (years) $^{1}$ & $6(2-11)$ & $7(4-15)$ & $6(2-20)$ \\
CAMCOG $^{1}$ & $10(0-57)$ & $21(0-46)$ & $7(0-57)$ \\
Family history & 1 & 2 & 3 \\
Clin. dementia rating & $1 / 2 / 8$ & $0 / 2 / 10$ & $0 / 2 / 12$ \\
(mild/moderate/severe) & & & \\
Depression & 1 & 4 & 4 \\
Delusion/hallucinations & $1 / 3$ & $3 / 5$ & $1 / 1$ \\
Myoclonus & 1 & 4 & 2 \\
Snout/grasp reflex & $3 / 3$ & $5 / 2$ & $7 / 5$ \\
\hline
\end{tabular}

${ }^{1}$ Median (range).

parahippocampo-parietal" component and a "coeruleo-frontal" component.

(2) Three patterns of neuronal change emerged from a cluster analysis: hippocampo-parahippocampoparietal cell loss (Cluster A), well-preserved neuron numbers (Cluster B), and coeruleo-frontal cell loss (Cluster $\mathrm{C}$ ). 
(3) The patient groups defined by these patterns tended to show different psychopathological, neurological and neuropathological features.

It has been shown that neurodegeneration in $\mathrm{AD}$ may extend along interconnected areas of the brain (Pearson et al., 1985; Fewster et al., 1991). The anatomical connection between the hippocampus, parahippocampus and parietal lobe is well established (Duvernoy, 1988; Cavada and Goldman-Rakic, 1989). In most cases of AD, changes in the hippocampus are severe and may precede less severe changes in other brain areas (Fewster et al., 1991; Förstl et al., 1993). A recent computed tomography and single photon emission tomography study demonstrated a close morphological and functional association between changes in the mediotemporal and parietal lobe occurring in the course of $\mathrm{AD}$ (Jobst et al., 1992). Connections of similar functional importance may exist between the locus coeruleus and frontal lobe areas. Parallel changes of neuron numbers in the locus coeruleus and Area 32 may relate to neocortical noradrenergic projections which are most intense to the frontal lobe (Nagai et al., 1981; Pearson et al., $1990)$. Dopamine- $\beta$-hydroxylase, the noradrenaline synthesizing enzyme, is decreased in $\mathrm{AD}$ and this decrease is most severe in the frontal lobe (Adolfsson et al., 1979; Cross et al., 1981). The noradrenaline concentration in the frontal lobe is significantly correlated with the neuron numbers in the locus coeruleus (Ichimaya et al., 1986). It has been hypothesized that neurodegeneration in AD may start in the aminergic brainstem nuclei (Hertz, 1989). A previous report indicated that this may be the case in patients with prominent affective disturbance early in the course of AD (Förstl et al., 1992a). Regarding our first question, we hypothesize that the statistical relationship between neuron numbers in various areas of the brain may reflect anatomical connections shown in previous work and that these connections represent potential pathways of neurodegeneration in AD.

Alzheimer (1911) felt that the extent of neurofibrillary deposition may characterize subtypes of AD. It has been shown that patients with higher neurofibrillary tangle density have more severe clinical deficits and neuropathological changes (Terry et al., 1987). This is in line with our findings in Cluster $\mathrm{C}$, where patients had the highest intraneuronal tangle counts and the longest duration of illness. Our data indicate an association with "frontal" release signs and affective disturbance, the latter relating to neuron loss in the locus coeruleus (Förstl et al., 1992a, b).

Bondareff $(1982,1987)$ distinguished mild senile AD1 from presenile AD2 with high genetic loading, rapid deterioration and severe neuropathological changes, typically a marked cell loss in the locus coeruleus. The patients in Cluster $\mathrm{C}$ did have the earliest onset and longest duration of illness, a positive family history in three cases and the worst cognitive performance, but none of these differences was statistically significant $(p>0.10)$. Berrios (1985) thought that a syndrome of "presbyophrenia" with predominant mnestic disturbance, confabulation and elated mood was related to neuronal loss in the locus coeruleus. This view cannot be supported by our data. They are in agreement with neuroimaging studies which described a subgroup of patients with clinically diagnosed $\mathrm{AD}$ and frontal hypometabolism (e.g. Haxby et al., 1988). A recent investigation suggested a relationship between decreased frontal glucose metabolism or neuropsychological "frontal" lobe function and a faster progression of illness (Mann et al., 1992).

Conversely, "parietal" lobe changes - sensory aphasia, visual agnosia, apraxia or even decreased radiodensity - have been related to rapid cognitive decline and increased mortality (McDonald, 1969; Naguib and Levy, 1982). These findings have not been replicated unequivocally (Gilleard et al., 1987; O'Carroll et al., 1991) and cannot be verified by our results. The patients in Cluster A with low hippocampo-parahippocampo-parietal neuron numbers had the shortest duration of illness, but this effect was not significant $(p>0.10)$.

The patient sample in our study was strongly biased towards senile dementia with a late onset of illness (Burns et al., 1990a). The majority of the patients who came to post-mortem examination had reached a severe clinical stage of dementia according to CDR (Berg, 1984). Thus, neither large variations of demographic variables nor of cognitive test profiles were to be expected. These variables had contributed to the characterization of subtypes in earlier studies (Chen et al., 1991; Chiu et al., 1985; Mayeux et al., 1985; Nyth et al., 1991). Psychopathological, neurological and histopathological features however showed differences between Clusters A, B and C and these differences were in agreement with our previous analyses (Förstl et al., 1992a, b).

It is still a matter of debate whether the clinical or neuropathological heterogeneity of manifestations can be subdivided into meaningful "subtypes" of AD (Jorm, 1985; Chui, 1987; Mohr et al., 1990). The term "subtype" is open to different interpretations and the varying emphasis placed by previous authors may have contributed to the divergent and sometimes incompatible attempts at subclassification. Cluster analysis tends to yield results even if the data under investigation lack a clear structure (Everitt, 1989). 
This may represent an additional source of conflicting results between cross-sectional studies based on different types of clinical information. In order to avoid a delineation of spurious or artefactual clusters we felt that the evidence for neuropathological subtypes should be strengthened by corresponding evidence of clinical differences between these clusters.

Our results suggest that subtypes of AD may be based on different patterns of neurodegeneration. It is unlikely that these subtypes are related to the admixture of other degenerative brain changes which had been allowed for by careful clinical and neuropathological examination. Patients with predominant coeruleo-frontal changes may benefit from different therapeutic strategies than those with predominant hippocampo-parahippocampo-parietal neurodegeneration. This and the stability of potential course characteristics will need further prospective investigation before the existence of subtypes of AD can be legitimately claimed (Jorm, 1985).

\section{Acknowledgements}

We acknowledge the statistical advice of Professor B. Everitt and Dr G. Dunn. This work was supported by grants from the Medical Research Council, by the German Research Foundation, by a Parke Davis Research Fellowship and by an H. \& L. Schilling professorship to H.F.

\section{REFERENCES}

Adolfsson R, Gottfries CG, Roos BE and Winblad B (1979) Changes in the brain catecholamines in patients with dementia of the Alzheimer type. British Journal of Psychiatry, 135, 216-223.

Alzheimer A (1911) Über eigenartige Krankheitsfälle des späteren Alters. Zeitschrift für die Gesamte Neurologie und Psychiatrie, 4, 356-385. Transl.: On certain peculiar diseases of old age. (1991) History of Psychiatry, 2, 71101.

Berg L (1984) Clinical dementia rating. British Journal of Psychiatry, 145, 339.

Berrios G (1985) Presbyophrenia: Clinical aspects. British Journal of Psychiatry, 147, 76-79.

Bondareff W, Mountjoy C and Roth M (1982) Loss of neurons of origin of the adrenergic projection to cerebral cortex (nucleus locus coeruleus) in senile dementia. Neurology, 32, 164-168.

Bondareff W, Mountjoy CQ, Roth M, Rossor MN, Iversen L and Reynolds GP (1987) Age and histopathological heterogeneity in Alzheimer's disease: evidence for subtypes. Archives of General Psychiatry, 44, 412-417.

Burns A, Jacoby R and Levy R (1990a) Psychiatric phenomena in Alzheimer's disease. British Journal of Psychiatry, 157, 72-94.

Burns A, Jacoby R and Levy R (1990b) Neurological signs in Alzheimer's disease. Age and Ageing, 20, 45-51.

Cavada C and Goldman-Rakic PS (1989) Posterior parietal cortex in rhesus monkey: I. Parcellation of areas based on distinctive limbic and sensory corticocortical connections. Journal of Comparative Neurology, 287, 357-372.
Chen J-Y, Stern Y, Sano M and Mayeux R (1991) Cumulative risks of developing extrapyramidal signs, psychosis, or myoclonus in the course of Alzheimer's disease. Archives of Neurology, 48, 1141-1143.

Chui HC (1987) The significance of clinically defined subgroups of Alzheimer's disease. Journal of Neural Transmission, 24 (Suppl), 57-68.

Chui HC, Lee Teng E, Henderson VW and Moy AC (1985) Clinical subtypes of dementia of the Alzheimer type. Neurology, 35, 1544-1550.

Copeland JRM, Kelleher MJ, Kellett JM, Gourlay AJ, Gurland BJ, Fleiss JL and Sharpe L (1976) A semistructured clinical interview for the assessment of diagnosis and mental state in the elderly: the Geriatric Mental State Schedule. I. Development and reliability. Psychological Medicine, 6, 439-449.

Cross AJ, Crow TJ, Perry EK, Perry RH, Blessed G and Tomlinson BE (1981) Reduced dopamine-beta-hydroxylase activity in Alzheimer's disease. British Medical Journal, 282, 93-94.

Duvernoy HM (1988) The Human Hippocampus. JF Bergmann, München.

Everitt BS (1989) Statistical Methods for Medical Investigation. Edward Arnold, London.

Everitt BS and Dunn G (1983) Advanced Methods of Data Exploration and Modelling. Heinemann, London.

Fewster PH, Griffin-Brooks S, MacGregor J, Ojalvo-Rose E and Ball MJ (1991) A topographical pathway by which histopathological lesions disseminate through the brain of patients with Alzheimer's disease. Dementia, 2, 121-132.

Förstl H, Burns A, Luthert P, Cairns N, Lantos P and Levy R (1992a) Clinical and neuropathological correlates of depression in Alzheimer's disease. Psychological Medicine, 22, 877-884.

Förstl H, Burns A, Levy R, Cairns N, Luthert P and Lantos P (1992b) Neurologic signs in Alzheimer's disease: results of a prospective clinical and neuropathologic study. Archives of Neurology, 49, 1038-1042.

Förstl H, Burns A, Levy R and Cairns N (1993) Neuropathological basis for drawing disability (constructional apraxia) in Alzheimer's disease. Psychological Medicine, 23, 623-629.

Gilleard CJ, Spain E and O'Carroll RE (1987) Senile dementia and parietal lobe dysfunction. British Journal of Psychiatry, 150, 114-117.

Gurland BJ, Fleiss JL, Goldberg L, Sharpe C, Copeland J, Kelleher M and Kellett J (1976) A semi-structured clinical interview for the assessment of diagnosis and mental state in the elderly: the Geriatric Mental State Schedule. II. A factor analysis. Psychological Medicine, 6, 451-459.

Haxby JV, Grady CL, Koss E, Horwitz B, Shapiro M, Friedland RP and Rapoport SI (1988) Heterogeneous anterior-posterior metabolic patterns in dementia of the Alzheimer type. Neurology, 38, 1853-1863.

Hertz L (1989) Is Alzheimer's disease an anterograde degeneration, originating in the brainstem, and disrupting metabolic and functional interactions between neurons and glial cells. Brain Research Bulletin, 14, 335-353.

Ichimaya Y, Arai H, Kosaka K and Iizuka R (1986) Morphological and biochemical changes in the cholinergic and monoaminergic systems in Alzheimer-type dementia. Acta Neuropathologica, 70, 112-116.

Jobst KA, Smith AD, Barker CS, Wear A, King EM, Smith A, Anslow PA, Molyneux AJ, Shepstone BJ, 
Soper N, Holmes KA, Robinson JR, Hope RA, Oppenheimer C, Brockbank K and McDonald B (1992) Association of atrophy of the medial temporal lobe with reduced cerebral blood flow in the posterior parietotemporal cortex in patients with a clinical and pathological diagnosis of Alzheimer's disease. Journal of Neurology, Neurosurgery and Psychiatry, 55, 190-194.

Jorm AF (1985) Subtypes of Alzheimer's dementia: a conceptual analysis and critical review. Psychological Medicine, 15, 543-553.

Mann UM, Mohr E, Gearing M and Chase TN (1992) Heterogeneity in Alzheimer's disease: progression rate segregated by distinct neuropsychological and cerebral metabolic profiles. Journal of Neurology, Neurosurgery and Psychiatry, 55, 956-959.

Maxwell SE and Delaney HD (1990) Designing Experiments and Analyzing Data. Wadsworth, Belmont, CA.

Mayeux R, Stern Y and Spanton S (1985) Heterogeneity in dementia of the Alzheimer type: evidence of subgroups. Neurology, 35, 53-61.

McDonald C (1969) Clinical heterogeneity in senile dementia. British Journal of Psychiatry, 115, 267-271.

McKhann G, Drachman D, Folstein M, Katzman R, Price D and Stadlan EM (1984) Clinical diagnosis of Alzheimer's disease: report of the NINCDS-ADRDA work group under the auspices of the Department of Health and Human Services Task Force on Alzheimer's disease. Neurology, 34, 939-944.

Mohr E, Mann UM and Chase TN (1990) Subgroups of AD: fact or fiction? Psychiatric Journal of the University of Ottawa, 15, 203-204.

Nagai T, Satoh K, Imamoto K and Maeda T (1981) Divergent projection of the locus coeruleus as revealed by fluorescent retrograde double labeling technique. Neuroscience Letters, 23, 117-123.

Naguib M and Levy R (1982) Prediction of outcome in senile dementia, a computed tomography study. British Journal of Psychiatry, 140, 263-267.

Norusis MJ (1988) SPSS V 2.0: Advanced Statistics. SPSS, Chicago, IL.

Nyth AL, Gottfries CG, Blennow K and Brane G (1991) Heterogeneity of the course of Alzheimer's disease: a differentiation of subgroups. Dementia, 2, 18-24.

O'Carroll R, Whittick J and Baikie E (1991) Parietal signs and sinister prognosis in dementia. British Journal of Psychiatry, 158, 358-361.

Pearson J, Halliday G, Sakamoto N and Michel J-P (1990) Catecholaminergic neurons. In: The Human Nervous System (Ed. G Paxinos), pp. 1023-1049. Academic Press, San Diego.

Pearson RCA, Esiri MM, Hiorns RW, Wilcock GK and Powell TPS (1985) Anatomical correlates of the distribution of the pathological changes in the neocortex in Alzheimer's disease. Proceedings of the National Academy of Science, 82, 4531-4534.

Roth M, Tym E, Mountjoy C, Huppert F, Hendrie H, Verma S and Goddard R (1986) CAMDEX: a standardized instrument for the diagnosis of mental disorder in the elderly with special reference to the early detection of dementia. British Journal of Psychiatry, 149, 698709.

Terry RD, Hansen LA, DeTeresa R, Davies P, Tobias H and Katzman R (1987) Senile dementia of the Alzheimer type without neocortical neurofibrillary tangles. Journal of Neuropathology and Experimental Neurology, 46, 262268.

Ward JH (1963) Hierarchical grouping to optimize an objective function. Journal of the American Statistical Association, 58, 236-244.

(Received January 1994; accepted as revised 7 July 1994) 


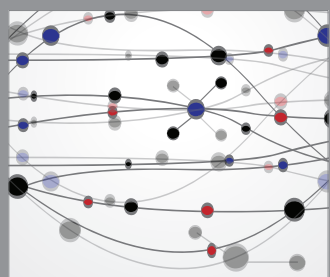

The Scientific World Journal
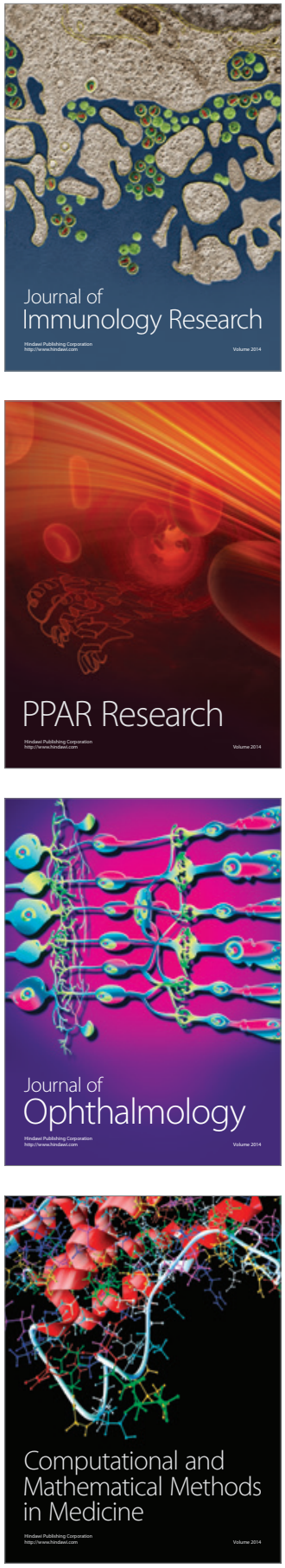

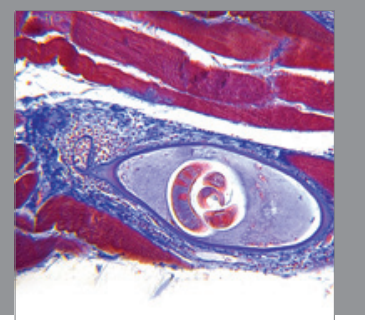

Gastroenterology

Research and Practice
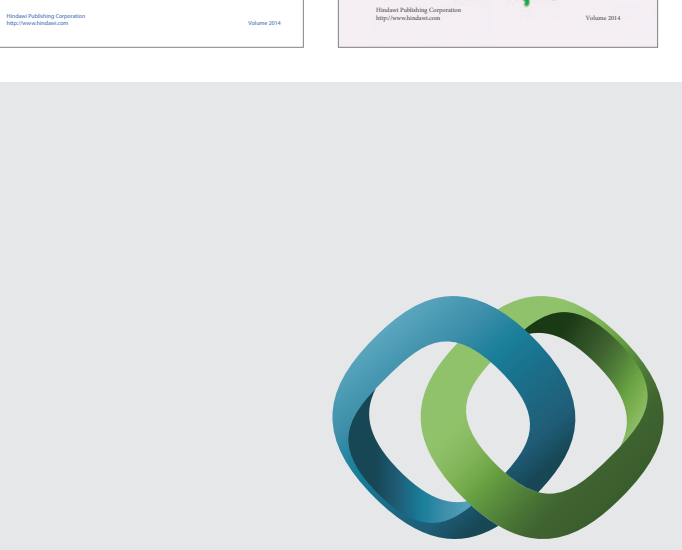

\section{Hindawi}

Submit your manuscripts at

http://www.hindawi.com
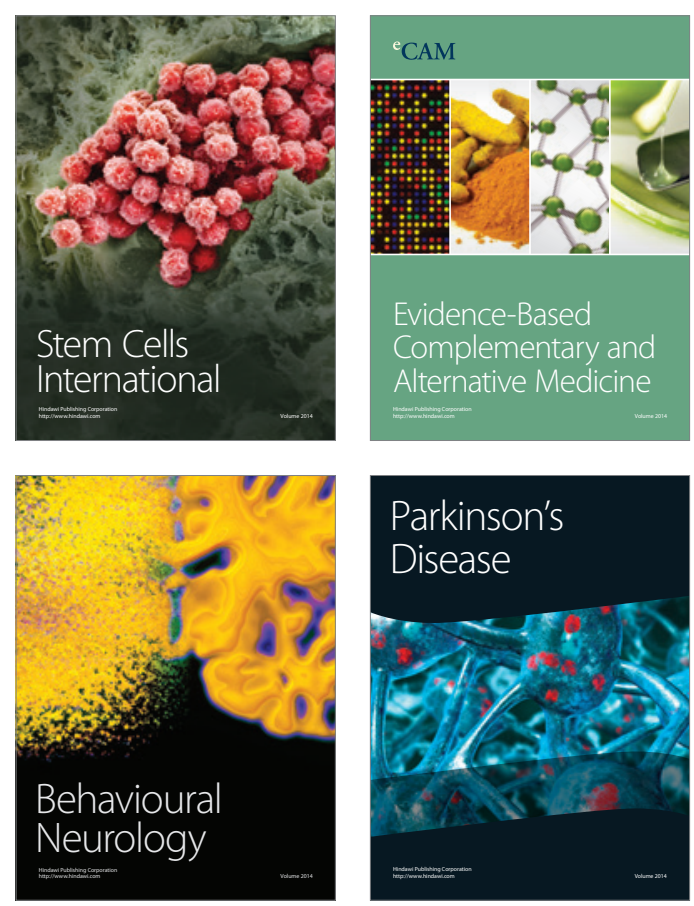

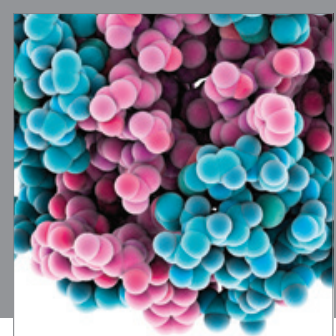

Journal of
Diabetes Research

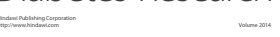

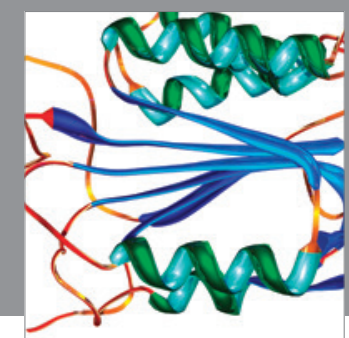

Disease Markers
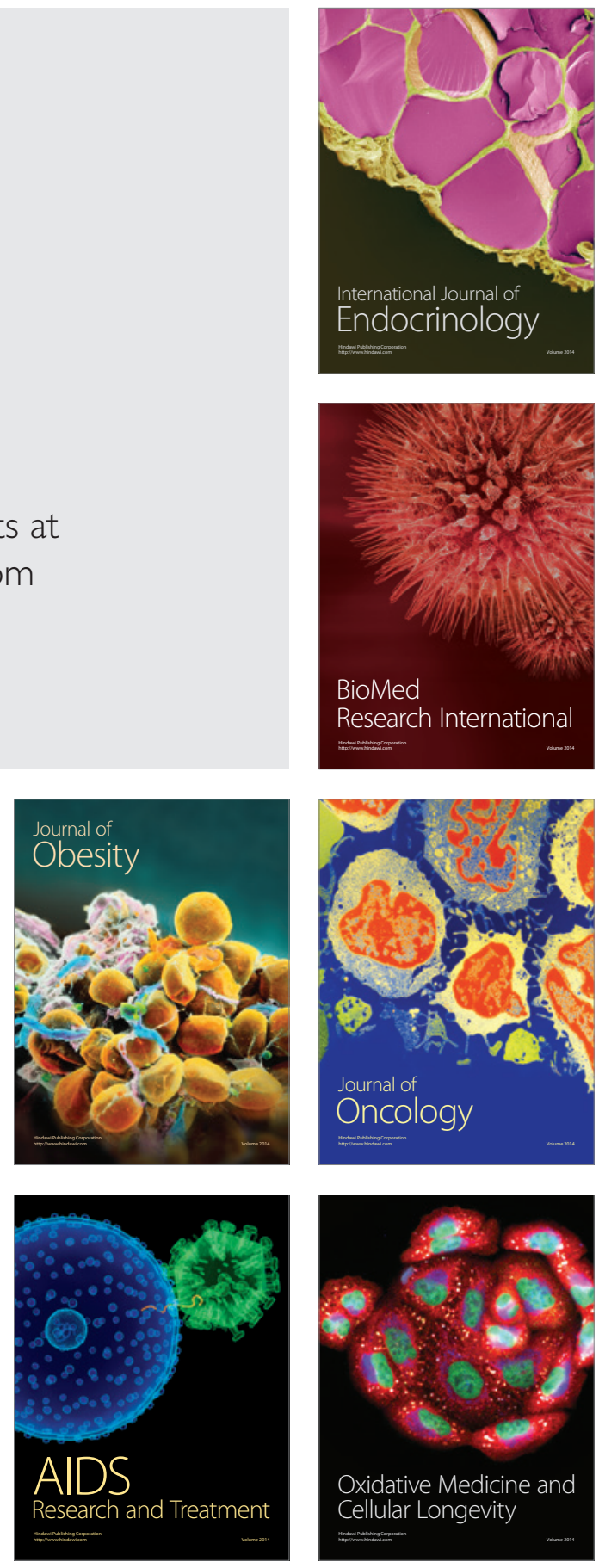